\title{
LEYENDO A FERRAJOLI: CONSIDERACIONES SOBRE LA JURISDICCIÓN *
}

\author{
Michele Taruffo ** \\ Universidad de Pavía
}

RESUMEN. Los aspectos de la obra de L. FeRRAJoli que más atraen la atención de los procesalistas son los relacionados con la administración de justicia y los caracteres de la jurisdicción. El punto de partida fundamental queda fijado por FERRAJOLI al subrayar que la jurisdicción es una garantía secundaria para asegurar la protección judicial de los derechos. Y esta garantía tiene que ser general, ya que ningún derecho existe realmente sin una protección efectiva por parte de los tribunales.

En el contexto judicial, la justicia resulta bien administrada cuando las normas jurídicas se aplican correctamente y la verdad de los hechos en disputa se determina de acuerdo con las pruebas, tal como pretende la teoría clásica de la toma de decisiones judiciales. Sin embargo, pueden plantearse aquí algunos problemas (que son fácilmente resolubles), si tomamos en consideración los poderes discrecionales —que tienen muchos jueces- para interpretar las normas creando nuevos derechos y los casos en que «remedies precede rights».

En cualquier caso, FERRAJOLI rechaza la denominada «objeción contra-mayoritaria», subrayando que la fundamentación principal del papel de los jueces no radica en su elección popular sino en su actuación de acuerdo con el Derecho.

Palabras clave: FERRAJOLI, jurisdicción, poderes discrecionales.

ABSTRACT. The proceduralist's attention is attracted mainly by the aspects of FERRAJOLI's work dealing with the administration of justice and the characters of jurisdiction. The basic starting point is when FERRAJOLI stresses that jurisdiction is a secundary guarantee ensuring the judicial protection of rights. Such a guarantee has to be general, since no right actually exists without an effective protection offered by courts.

In judicial contexts justice is properly administered when legal rules are correctly applied and the truth of the facts in issue is established according to evidence and proof, as the classical theory of judicial decision-making claims. Some problems may arise, however, but may be easily solved, when one takes into account the discretionary powers - belonging to many judges - to interpret the rules creating new rights, and the cases in which «remedies precede rights».

At any rate, FERRAJOLI rejects the so-called «countermajoritarian objection» outlining that the basic foundation of judge's role is not a popular election but relies upon the judge's compliance with the law.

Keywords: FERRAJOLI, jurisdiction, discretionary powers.

\footnotetext{
* Fecha de recepción: 1 de diciembre de 2008. Fecha de aceptación: 18 de diciembre de 2008.

** Cfr. FERRAJOLI, 2007: Principia iuris. Teoria del diritto e della democrazia, 1. Teoria del diritto; 2. Teoria della democrazia. 3. La sintassi del diritto, Bari. Este artículo reproduce la intervención llevada a cabo durante el seminario sobre Diritto e democrazia costituzionale. Discutendo Principia Juris di L. Ferrajoli, realizado en la Università di Bresica el 6 y 7 de diciembre de 2007.
} 


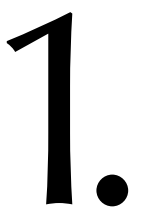

Si se hojea la obra magna de L. FERRAJOLI, es normal que la atención de un procesalista se concentre de forma especial en los puntos en los que el autor se ocupa de la jurisdicción y de las funciones que ésta cumple o debería cumplir en el contexto de un sistema democrático y de tutela de los me propongo realizar algunas observaciones.

El punto de partida del discurso es la calificación de la jurisdicción como garantía secundaria, cuya función fundamental consiste en asegurar la justiciabilidad de las violaciones de los derechos ${ }^{1}$. FERRAJOLI aclara que se trata de garantías reparatorias que tienen la finalidad de eliminar o reducir el daño producido, o de intimidar y castigar a los responsables ${ }^{2}$, y que la jurisdicción no garantiza la satisfacción inmediata de los derechos, dado que este es el carácter propio de las garantías primarias, pero asegura la anulabilidad de los actos inválidos y la sanción de los actos ilícitos realizados en violación de las garantías primarias ${ }^{3}$. Aclara también que de hecho las garantías secundarias, y entre ellas la jurisdicción, pueden no darse y presuponen la creación de aparatos judiciales capaces de aplicarlas adecuadamente ${ }^{4}$. Finalmente, FERRAJOLI precisa que las garantías jurisdiccionales se articulan en una serie de sub-garantías de carácter específicamente procesal, como las reconocidas habitualmente en normas constitucionales o en principios fundamentales del proceso 5 .

No se puede estar en desacuerdo con las líneas generales de esta concepción de las garantías jurisdiccionales (salvo alguna precisión que haré enseguida). Ésta tiene, en efecto, la ventaja de establecer con claridad la función fundamental de la jurisdicción como instrumento indispensable de la implementación de los derechos. Por un lado, esto implica que se abandonen fórmulas habituales como las que sostienen que la justicia es un servicio, una empresa, una rama de la administración pública, etc., siguiendo una línea de desvalorización de la jurisdicción que se combina con la exaltación de las diversas formas de justicia «privada», como si la verdadera justicia la hicieran los árbitros (escogidos y pagados por las partes) y no los jueces (preconstituidos por ley y no retribuidos por sus «usuarios»).

Por otro lado, destaca claramente que la garantía jurisdiccional no puede no tener carácter general, en el sentido de que —al menos en principio— no existe realmente derecho alguno si éste no está acompañado de tutela jurisdiccional. Decir —como se hace a veces- que un derecho existe pero no goza de garantías jurisdiccionales y, por tanto, no es susceptible de una acción ante un juez, supone no haber entendido el vínculo intrínseco que debe darse, precisamente, entre la existencia de un derecho y la posibilidad de hacerlo valer en juicio en caso de violación o falta de implementación. FERRAJOLI apunta un fenómeno gravísimo, constituido por el hecho de que numerosos derechos fundamentales, a veces garantizados constitucionalmente, siguen careciendo de protección, en la medida en que no permiten ejercer una acción judicial y destaca, en particular, entre esos «derechos sin tutela» los «derechos

\footnotetext{
1 Op. cit., 1., pp. 675 y ss.

2 Ibidem.

Ibidem.

${ }^{4}$ Op. cit., 1, p. 677.

5 Op. cit., 1, p. 678.
} 
sociales» ${ }^{6}$. Este fenómeno existe, ciertamente, y constituye una de las lagunas más graves de los sistemas jurídicos actuales, empezando por el italiano. Al respecto, la denuncia de FERRAJOLI es debida y no puede más que ser compartida. La triste observación que se puede hacer es que vivimos en sistemas que se contentan con hacer vacías proclamaciones retóricas de los derechos fundamentales, olvidando que sin garantía jurisdiccional no se trata más, precisamente, que de vacías proclamaciones retóricas.

2. El discurso de FERRAJOLI sobre la jurisdicción prosigue abordando la identificación de sus caracteres fundamentales, en particular: a) la aplicación a los casos concretos de las normas sustantivas violadas; y $b$ ) la determinación de los hechos sobre la base de las pruebas, como premisa necesaria para la adecuada aplicación de las normas substantivas ${ }^{7}$. FERRAJOLI subraya, oportunamente, que el núcleo central de la jurisdicción consiste en la determinación del supuesto de hecho sujeto a juicio, en un acto declarativo o cognitivo con el que el juez determina los hechos y su nomen juris, aplicando las normas a los hechos. Textualmente: «el juicio es, en efecto, prueba del hecho, a la que es aplicada la norma y, a la vez, interpretación operativa de la norma aplicada al hecho» ${ }^{8}$. A este análisis del juicio jurisdiccional se remite FERRAJOLI cuando dice, en otra parte, retomando las mismas definiciones y vinculándolas directamente con el principio de estricta legalidad que rige siempre que la jurisdicción desarrolla la función que le es propia, de aplicación sustantiva y, por tanto, de afirmación de la ley?.

En esta forma de configurar la naturaleza fundamental de la jurisdicción resuenan las doctrinas clásicas acerca de la decisión judicial como aplicación de la ley substantiva a los hechos del caso concreto que hayan sido objeto de una adecuada demostración probatoria, cosa que no es nueva en FERRAJOLI. Esto no impide, sin embargo, que pueda hacerse alguna observación sobre la misma e incluso plantear alguna duda.

Por un lado, poner tan clara y decididamente el acento en la aplicación de las normas sustantivas en la decisión judicial permite dejar a un lado las teorías, que florecen especialmente, pero no sólo, en Estados Unidos, según las cuales la única justicia de la que se puede hablar en el ámbito de la jurisdicción es la justicia del proceso. En la cultura jurídica y filosófica norteamericana la idea de la procedural justice, en sus distintas versiones (desde RAWLS a los psicólogos experimentales) ${ }^{10}$, ha tenido primordialmente el efecto de distraer la atención de la justicia o injusticia «sustancial» de la decisión judicial para concentrar el discurso sobre la justicia o injusticia del procedimiento, como si ésta pudiera absorber a aquélla, o asegurase a priori, la justicia del resultado final del procedimiento. Se trata de un discurso que no es nuevo (parecido al propuesto por LuHMANN en Legitimation durch Verfabren), que tiende a poner el acento en la legitimación y aceptabilidad de la decisión judicial, más que en su justicia substancial: de ésta, por otra parte, se olvidan los adeptos de la procedural justice. Las versiones italianas de concepciones como éstas se concentran —como es sa- 
bido- en la idea del «justo proceso», que ha sido tan influyente que ha llevado incluso a la reforma del art. 111 de la Constitución ${ }^{11}$. Más allá de las contingentes motivaciones políticas (se trata, en realidad, de hacer «justo» el proceso penal para algunos imputados excelentes) y del hecho que las garantías fundamentales del proceso ya existían desde hace tiempo, éste ha sido un factor que, una vez más, ha llevado a muchos a sostener que la función de la jurisdicción se agota en asegurar la justicia de los procedimientos jurisdiccionales, pero no involucra a la justicia sustancial de las decisiones judiciales. Respecto de estas concepciones, muy discutibles pero no por ello menos difundidas, el fuerte énfasis de FERRAJOLI en que la función esencial de la jurisdicción es la afirmación y la aplicación de la ley sustantiva y, por tanto, de la correcta aplicación de la ley como condición esencial de la justicia de las decisiones, debe tomarse en muy seria consideración. Cuando se trata de asegurar la implementación de los derechos fundamentales, pero también cuando se trata de determinar cualquier otra situación jurídica, la idea de que se hace justicia llevando a cabo un procedimiento fair, pero no asegurando la correcta aplicación de la ley, debería resultar al menos curiosa.

Por otro lado, resulta no menos esencial la afirmación de FERRAJOLI, confirmada y repetida en diversas ocasiones, según la cual la garantía jurisdiccional implica la determinación, basada en las pruebas, de la verdad de los hechos que están en la base de la controversia: «la legitimidad de la decisión reside en la garantía de la determinación imparcial de la verdad» ${ }^{12}$. También a este respecto FERRAJOLI hace referencia a concepciones clásicas sobre la naturaleza de la decisión judicial, de la función de la prueba y de la necesidad de una determinación verdadera de los hechos del caso. No se puede obviar, sin embargo, incluso adhiriendo absolutamente a la tesis de FERRAJOLI, que ésta va —en el panorama actual — netamente a contracorriente.

Ante todo, aunque parezca producirse una suerte de «retorno a la verdad» en el plano filosófico y epistemológico ${ }^{13}$, los veriphobics y los deniers de la verdad ${ }^{14}$ son aún numerosos, especialmente entre los juristas y, en particular, entre los procesalistas ${ }^{15}$. En realidad, no todos los procesalistas comparten posiciones escépticas o indiferentes sobre el problema de la determinación de la verdad en el proceso ${ }^{16}$. Sin embargo, es importante que FERRAJOLI considere central entre las condiciones para la implementación de las garantías jurisdiccionales la determinación de la verdad sobre los hechos. Las razones por las que es importante son, al menos, dos. La primera es que la justi-

${ }^{11}$ La reforma ha provocado una literatura amplísima, sin duda desproporcionda respecto de la importancia real del tema. Al respecto, cfr., por todos, Comoglio, 2004: Etica e tecnica del «giusto processo», Torino; CHIARLONI, 2000: «Il nuovo articolo 111 della Costituzione e il processo civile», en Riv. dir. proc., pp. 1010 y ss.

${ }^{12}$ Op. cit., 2, p. 214

${ }_{13}$ Entre la literatura italiana reciente, $c f r$., por ejemplo, MARCONI, 2007: Per la verità. Relativismo e filosofia, Torino; 2007: Conoscenza e verità, M. C. AMORETTI y M. MARSONET, 2005 (eds.), Milano: La verità. Scienza, filosofia, società, S. BORUTTI y L. FonNEsu (eds.), Bologna. Cfr. también, a parte de las obras de Goldman y de WILLIAMS citadas en la nota siguiente, LYNCH, 2004: La verità e i suoi nemici, tr. it. Milano.

${ }^{14}$ La primera definición es de Goldman, 1999: Knowledge in A Social World, Oxford, pp. 7 y 9; la segunda es de Williams, 2002: Truth and Truthfulness. An Essay in Genealogy, Princeton-Oxford, p. 5.

${ }^{15} \mathrm{Al}$ respecto, vid., más ampliamente, TARUFFO, 1992: La prova dei fatti giuridici. Nozioni generali, Milano, pp. 7 y ss.

${ }_{16}$ Aparte del autor de estas páginas, sobre el que puede verse la nota precedente, $c f r$, en particular, UBERTIS, 2007: Sistema di procedura penale. I. Principi generali, 2. ${ }^{a}$ ed., Torino, pp. 53 y ss. 
cia de la decisión judicial no puede dejar de suponer, como condición necesaria (aunque, obviamente, no suficiente), la determinación de la verdad de los hechos sujeto de la controversia: como muchos piensan, ninguna decisión puede considerarse justa si se funda en una reconstrucción errónea de los hechos ${ }^{17}$. La segunda razón es que de esta forma se puede «reorientar» la función de las pruebas en un sentido epistémico, es decir, considerándolas como instrumentos para el descubrimiento de la verdad en el proceso, abandonando las recurrentes concepciones de la prueba como instrumento puramente retórico cuyo objetivo es producir una persuasión favorable en la mente del juez ${ }^{18}$.

La referencia a la determinación de la verdad de los hechos produce también consecuencias respecto de la forma de concebir el proceso y su función (o, si se prefiere, respecto de la ideología del proceso y de sus finalidades). Las teorías de la procedural justice mencionadas anteriormente excluyen de su radio de atención la calidad y el contenido de la decisión final y, por tanto -obviamente-, no tienen en cuenta en absoluto la eventualidad de que la verdad de los hechos sea o no establecida. Es más, se puede añadir que el sistema procesal al que estas teorías se adaptan mejor, esto es, el adversarial system norteamericano, no sólo resulta estructuralmente incapaz de asegurar el descubrimiento de la verdad, sino que está orientado, precisamente, en sentido opuesto: como dicen sus teóricos más coherentes, en el proceso adversarial la verdad no sólo no es un fin perseguible sino que es, incluso, fastidiosa y contraproducente ${ }^{19}$. El problema es, sin embargo, de orden más general y, aquí, podrá ser sólo apuntado: deriva del hecho de que - como se observa a través del análisis estructural de los modelos procesales - si nos encontramos en un sistema procesal orientado exclusivamente a la resolución de la controversia e incardinado exclusivamente sobre la actividad de las partes, la verdad de los hechos no constituye ciertamente un objetivo que se considere digno de ser perseguido y, es más, puede ser un obstáculo a la solución eficiente del conflicto ${ }^{20}$. Esta observación no es válida sólo para el proceso norteamericano, y puede valer en línea general para todos los tipos de procedimiento que estén estructuralmente fundados en la libre iniciativa de las partes y en la idea de que el proceso consiste en una competición en la que aquéllas combaten frente a un juez pasivo y neutral. Surge, pues, una tensión - si no un verdadero conflicto- entre el valor representado por la determinación de la verdad como condición de justicia y de legalidad de la decisión y la idea de que el proceso es simplemente un lugar de enfrentamiento y de competición individual, que lleva por definición a una solución aceptable de la controversia.

Una implicación adicional de lo que dice FERRAJOLI acerca de la determinación de la verdad de los hechos afecta a la forma de concebir la cláusula constitucional del «justo proceso», ya mencionado, y también cualquier otro principio de justicia del proce-

${ }_{17}$ Más ampliamente al respecto, $c f r$ TARUFFO, Idee per una teoria della decisione giusta, ahora en ID., 2002: Sui confini. Scritti sulla giustizia civile, Bologna, pp. 219 y ss. 329 y ss.

${ }^{18}$ Sobre esta concepción vid., también para referencias adicionales, TARUFFO, La prova, cit., pp. 62, 284,

${ }^{19}$ Cfr., por ejemplo, LANDSMAn, 1984: The Adversary System. A Description and Defense, Washington-London, pp. 36 y ss.

${ }^{20}$ Cfr., en particular, el análisis ya clásico al respecto de DAMAŠKA, 1986: I volti della giustizia e del potere. Analisi comparatistica del processo, tr. it. Bologna, pp. 211 y ss. 
dimiento, due process of law, debido proceso legal, etc. En síntesis, el problema puede ser formulado en estos términos: ¿estamos dispuestos a considerar justo un proceso que no asegure la obtención de decisiones justas? Según la concepción más difundida, pero también más banal y repetitiva, para la que el proceso es justo si asegura las garantías previstas como tutela de las partes, la respuesta puede ser positiva: si la calidad de la decisión no se considera relevante, y la justicia del proceso se valora sin tomar en cuenta los resultados que se obtienen, está claro que un proceso puede ser justo (en el sentido ya mencionado de la procedural justice) aunque no asegure la justicia de las decisiones que produce. Se puede decir también — como dicen muchos sin preocuparse de la circularidad del argumento- que es justa en cualquier caso la decisión que deriva de un proceso justo.

La concepción que parece más sensata es, en cambio, la que lleva a una respuesta negativa a la pregunta formulada: es imposible considerar justo un proceso que - aunque haga efectivas las garantías de defensa de las partes- pueda concluir con una sentencia injusta. Si además se considera, como se ha dicho hace un momento, que la justicia de la decisión final depende también —necesariamente- de la determinación de la verdad de los hechos, se infiere que un proceso no es justo si no está estructuralmente orientado a la búsqueda y al descubrimiento de la verdad. Parece evidente, por otra parte, que un proceso que se desarrolla correctamente puede producir decisiones injustas, si resulta errónea la determinación final de los hechos o si la norma se aplica de forma equivocada. Esta conclusión parece inferirse claramente de premisas razonables y aceptables, pero implica consecuencias relevantes dado que - como demostraría cualquier análisis comparado- muchos ordenamientos procesales (y, en particular, el proceso civil italiano) no están en absoluto estructurados de forma que se permita que se determine la verdad de los hechos.

3. La apelación a las concepciones clásicas de la decisión judicial, que FERRAJOLI pone en el centro de su concepción de la jurisdicción, es ciertamente compartible en sus aspectos fundamentales. Sin embargo, puede suscitar algunas perplejidades si no se entiende correctamente. Se trata de perplejidades quizás marginales respecto del núcleo fundamental del discurso de FERRAJOLI, pero que pueden no ser absolutamente irrelevantes.

Una primera perplejidad surge del hecho de que, como se ha visto más arriba, uno de los caracteres fundamentales de la jurisdicción radica en la aplicación de las normas sustantivas al supuesto de hecho concreto. De esta forma, sin embargo, se corre el riesgo de caer de nuevo en una concepción deductivista $-\mathrm{o}$ incluso mecanicista- de la decisión, con un juez visto como mero «aplicador» de normas preexistentes y preconstituidas. La fuente de perplejidad radica en la constatación de que no siempre las cosas son así. Por un lado, no es extraño que el juez se encuentre en la situación de tener que decidir en ausencia de normas o de situaciones jurídicas preexistentes. Esto se produce siempre que se carece de una específica norma sustantiva ordinaria que gobierne el supuesto de hecho y, por tanto, se plantea la alternativa entre declarar que ese supuesto de hecho carece de calificación jurídica (y, en consecuencia, carece de tutela jurisdiccional) y buscar «en otra parte» (en las normas constitucionales directamente aplicables, en los principios generales del ordenamiento, en el common law, en la práctica comercial, etc.) un criterio sustantivo de juicio que permita calificar el supuesto de he- 
cho como jurídicamente relevante y, en consecuencia, considerarlo como tutelable en sede jurisdiccional. La respuesta a este problema no radica sólo en la conocida teoría de las lagunas y de los métodos para colmarlas: el centro del problema está en la configuración del poder del juez de buscar, y eventualmente crear, la regla sustantiva que necesita para decidir. Esto puede dar lugar a algún problema de aceptación en los ordenamientos de civil law, en los que se parte aún — aunque cada vez menos- de la premisa de que rights precede remedies, y que, por tanto, el juez debe determinar situaciones preexistentes de las que él está llamado a ocuparse. El mismo argumento crea menos problemas en los ordenamientos de common law, donde la premisa comúnmente aceptada es que remedies precede rights y que, por tanto, no hay nada extraño en que un derecho surja en el momento en que el juez declara que éste existe. Desde esta perspectiva, entonces, la función de la jurisdicción no es sólo declarar derechos una vez que éstos rigen, sino también crear derechos previamente inexistentes y que surgen precisamente con la decisión del juez que los reconoce.

Se intuye fácilmente que este problema asume una importancia especial precisamente en el ámbito de los derechos humanos y sociales: éstos surgen primero en la conciencia moral y social, y sólo después - a menudo con grave retraso- son reconocidos y regulados por los legisladores; y a veces, es más, este reconocimiento no se produce nunca. Así pues, si se limitase la función de la jurisdicción a declarar sólo lo que ya existe, se cerraría el camino a formas de garantía que podrían asegurar la ejecución de esos derechos, también en casos de inercia culpable de los legisladores. En algún caso, la prescripción de una jurisdicción «creativa» la realiza incluso el legislador: cuando, por ejemplo, la Constitución brasileña encarga al juez asegurar la ejecución de los derechos fundamentales — también en ausencia de normas legales ordinarias que los prevean- no hace otra cosa que atribuir a la jurisdicción una función de suplencia respecto de los otros poderes del Estado, precisamente con la finalidad de asegurar que los derechos fundamentales sean protegidos. Algo similar sucedió, en ausencia de previsiones normativas de todo tipo, con las institutional injunctions, creadas a partir de los años setenta por los tribunales estadounidenses: con este remedio procesal los jueces sustituyeron al legislador ordinario y a los órganos administrativos encargados de la tutela de los derechos fundamentales en el interior de instituciones como cárceles u hospitales. Fueron los jueces los que, en diversos casos, dispusieron — extendiendo sus poderes de una forma hasta entonces nunca vista - a la reorganización de estas instituciones: ejercitando, pues, un poder no sólo creativo sino incluso organizativo y administrativo.

Las situaciones mencionadas pueden constituir casos límite, pero también los casos límite pueden tener su relevancia para indicar un camino a seguir. No debe olvidarse, sin embargo, que se plantean problemas análogos — quizás de forma menos evidente pero con la misma importancia- cada vez que se trata de aplicar normas ya existentes, pero que reenvían a principios, a conceptos indeterminados o a cláusulas generales. Es conocido que en esos casos no se está ante una pura y simple discrecionalidad interpretativa y que el juez debe recurrir a la denominada hetero-interpretación de la norma que debe aplicarse. No hay nada nuevo a este respecto: queda, sin embargo, el hecho de que en todos esos casos el juez no debe sólo aplicar una norma preexistente, sino que dispone de un poder «creativo» en la identificación de la regla que deberá aplicar a los hechos. Además, en esta operación el juez puede tener que establecer qué hechos 
deben probarse a los efectos de concretar adecuadamente el significado de la norma «abierta» (lo que puede poner en discusión diversos principios, como aquél por el que corresponde a las partes el monopolio de las alegaciones de los hechos relevantes que constituyen la base de la controversia).

FERRAJOLI es perfectamente consciente de estos problemas - viejos y nuevos- y reconoce que aquí se plantea el problema fundamental de la discrecionalidad interpretativa ${ }^{21}$. Sin embargo, tiende a discutir el problema sólo en el ámbito del juicio de constitucionalidad, mientras que respecto de la jurisdicción ordinaria piensa en un espacio interpretativo más reducido, según el modelo de la subsunción de los hechos bajo normas preestablecidas. Así, FERRAJOLI subraya que la jurisdicción dispone de una «esfera de lo decidible más reducida que la que está abierta a la legislación», pero después reconoce que también la jurisdicción lleva a cabo una actividad «inevitablemente discrecional y marcada muy a menudo por juicios de valor» ${ }^{22}$. Se trata de apuntes interesantes, pero que no recogen, seguramente, la importancia y la frecuencia de las situaciones en las que la jurisdicción no se limita a interpretar/aplicar normas sustantivas, sino que crea ella misma las situaciones sustantivas en las que se dan efectivamente los derechos.

4. Por este camino se alcanza otro problema de gran importancia: si se atribuye a los órganos jurisdiccionales no sólo una función de interpretación/aplicación de la ley preexistente, sino también una función creativa, surge el problema de la legitimación de los jueces para crear Derecho. Se trata de un tema clásico de la división de poderes (sobre el que, no por casualidad, FERRAJOLI apela a MONTESQUIEU ${ }^{23}$ ) o —en términos más actuales- de la countermajoritarian objection, según la cual los jueces no electos y, por tanto, no legitimados por el consenso mayoritario, no podrían realizar actos de naturaleza sustancialmente legislativa. FERRAJOLI señala con razón ${ }^{24}$ que, de este modo, se opera una confusión entre dos tipos irreductiblemente distintos de legitimación: la electiva, típica del poder político, y aquella —-típica del poder jurisdiccional- caracterizada exclusivamente por la sujeción del juez a la ley. Por ello, considera inapropiada la solución consistente en elegir a los jueces, porque «el poder judicial es un poder-saber, más legítimo cuanto mayor es el saber» ${ }^{25}$. Se puede estar sin duda de acuerdo en el punto de que la elegibilidad de los jueces no resuelve el problema (y que, es más, crea muchos otros desde el punto de vista de la independencia y de la imparcialidad del propio juez), del mismo modo que se puede estar de acuerdo en el hecho de que el juez no tiene ninguna legitimación política y no tiene ninguna necesidad de ella. Queda, en cambio, el hecho de que los jueces - y no sólo los jueces constitucionales-, por voluntad o necesidad, se hacen, cada vez más a menudo y con efectos más relevantes, con espacios en los que llevan a cabo una actividad creativa del derecho. Como se ha dicho ya, en efecto, sucede cada vez más frecuentemente, por inercia o por incapacidad de los legisladores, y no sólo en los sistemas del common law, que remedies precede rights.

\footnotetext{
${ }^{21}$ Op. cit., 2, p. 74.

${ }_{22}$ Op. cit., 2, p. 75.

${ }_{23}$ Op. cit., 2, p. 213.

${ }^{24}$ Op. cit., 2, p. 214

${ }^{25}$ Ibidem.
} 
No parece infundada la impresión de que se trata de una tendencia probablemente imparable y que, en ocasiones, es también una tendencia elogiable, si ésta implica una cierta medida de stretching de los principios tradicionales con el fin de tutelar de forma efectiva los derechos. El problema de la legitimación de los jueces para llevar a cabo este papel deberá plantearse en un plano distinto: no el de la legitimación política de tipo electoral, sino el de la implementación efectiva de las garantías de independencia y de imparcialidad de la magistratura ${ }^{26}$.

(Traducción de Jordi Ferrer Beltrán)

${ }^{26}$ En este sentido véase op. cit., 2, p. 218. 
